\title{
Effect of Post Injections on Mixture Preparation and Unburned Hydrocarbon Emissions in a Heavy-Duty Diesel Engine
}

Jacqueline O'Connora, Mark Musculus ${ }^{b}$, and Lyle Pickett ${ }^{b}$

${ }^{a}$ Pennsylvania State University, University Park, PA

${ }^{b}$ Sandia National Laboratories, Livermore, CA

Contact information for corresponding author:

Jacqueline O'Connor

111 Research East Building

University Park, PA 16802

Email: jxo22@engr.psu.edu

Phone: 814.863.1502

\section{Abstract}

This work explores the mechanisms by which a post injection can reduce unburned hydrocarbon (UHC) emissions in heavy-duty diesel engines operating at low-temperature combustion conditions. Post injections, small, close-coupled injections of fuel after the main injection, have been shown to reduce UHC in the authors' previous work. In this work, we analyze optical data from laser-induced fluorescence of both $\mathrm{CH}_{2} \mathrm{O}$ and $\mathrm{OH}$ and use chemical reactor modeling to better understand the mechanism by which post injections reduce UHC emissions. The results indicate that post-injection efficacy, or the extent to which a post injection reduces UHC emissions, is a strong function of the cylinder pressure variation during the post injection. However, the data and analysis indicate that the pressure and temperature rise from the post injection combustion cannot solely explain the UHC reduction measured by both engine-out and optical diagnostics. The fluid-mechanic, thermal, and chemical interaction of the post injection with the main-injection mixture is a key part of UHC reduction; the starting action of the post jet 
and the subsequent entrainment of surrounding gases are likely both important processes in reducing UHC with a post injection.

\section{Keywords}

Low-temperature combustion, unburned hydrocarbon emissions, post injections, heavy-duty diesel

\section{Nomenclature}

\begin{tabular}{|l|l|}
\hline AEI & After end of injection \\
\hline AHRR & Apparent heat release rate \\
\hline BDC & Bottom dead center \\
\hline CAD & Crank angle degree \\
\hline DSE1 & Duration of solenoid energizing - main injection \\
\hline DSE2 & Duration of solenoid energizing - post injection \\
\hline EGR & Exhaust gas recirculation \\
\hline Energizing dwell & Time between end of main and beginning of post \\
& injection \\
\hline EOI & End of injection \\
\hline gIMEP & Gross indicated mean effective pressure \\
\hline HR & Homogeneous reactor - Chemkin reactor model \\
\hline Ignition dwell & Time between the end of injection and second- \\
\hline LTC & stage ignition \\
\hline
\end{tabular}




\begin{tabular}{|l|l|}
\hline $\mathrm{P}_{\mathrm{o}}$ & Initial pressure - in Chemkin simulation \\
\hline PLIF & Planar laser-induced fluorescence \\
\hline SOI & Start of injection \\
\hline SSE1 & Start of solenoid energizing - main injection \\
\hline SSE2 & Start of solenoid energizing - post injection \\
\hline$T_{\mathrm{AC}}$ & Adiabatic core temperature \\
\hline TDC & Top dead center \\
\hline$T_{\mathrm{FSP}}$ & Temperature of first-stage ignition products \\
\hline $\mathrm{T}_{\mathrm{mix}}$ & Mixture temperature after adiabatic mixing \\
\hline TSL & Two-stage Lagrangian - Chemkin reactor model \\
\hline $\mathrm{T}_{\mathrm{SSP}}$ & Temperature of second-stage ignition products \\
\hline UHC & Unburned hydrocarbons \\
\hline UV & Ultra-violet \\
\hline
\end{tabular}

\section{Introduction}

In this work, we explore the use of post injections- close-coupled, short injections after the end of the main fuel delivery- to reduce unburned hydrocarbon (UHC) emissions from heavy-duty diesel engines operating at low-temperature combustion (LTC) conditions. This multiple injection technique has shown some promise in previous studies [1], but the in-cylinder mechanisms by which post injections reduce UHC emissions are still unclear. Understanding the chemical and physical processes driving UHC emissions reduction using post injections is an important step toward increasing the viability of LTC strategies in heavy-duty diesel engines. 
LTC operation has the potential to reduce engine-out pollutant emissions, including soot and $\mathrm{NO}_{\mathrm{x}}$. Recently reviewed by Musculuset al.[1] and investigated for applications in both light-duty [2-6] and heavy-duty [7-10] engines, LTC uses a combination of greater dilution and premixing of reactant mixtures compared to conventional diesel combustion [11] to suppress formation of $\mathrm{NO}_{\mathrm{x}}$ and soot. One common method of dilution is exhaust gas recirculation (EGR), which introduces high-heat-capacity species such as $\mathrm{CO}_{2}$ and $\mathrm{H}_{2} \mathrm{O}$ into the cylinder, reduces the flame temperature, and thereby slows the chemical kinetics of thermal $\mathrm{NO}_{\mathrm{x}}$ formation.Reduced temperatures at LTC conditions can also decrease soot formation rates, but the lower oxygen concentration simultaneously yields an overall more fuel-rich charge, which can promote soot formation if pre-combustion mixing is not also modified. LTC strategies enhance precombustion mixing by injecting fuel at point in the cycle where the ignition delay is long compared to conventional diesel fuel-injection timings. In this way, the fuel and air are allowed more time to mix, resulting in mixtures that are less fuel-rich at ignition than for conventional diesel combustion, such that there is much less opportunity for soot formation. This can be achieved by injecting fuel either earlier $[10,12]$ or later $[6,13]$ than the conventional diesel fuelinjection schedule. With greater quantities of fuel premixing prior to combustion, peak heatrelease rates can be excessive for LTC conditions at high load, so LTC conditions are generally limited to low load.

Creating this long ignition-delay, highly dilute mixture before combustion can have undesired consequences on combustion efficiency. Previous studies $[14,15]$ have quantified fuel/air mixing at these conditions, showing that during the long ignition delay certain portions of the mixture can become too lean to ignite, resulting in lower combustion efficiency and increased UHC emissions. Toluene planar laser-induced fluorescence and Rayleigh-scattering mixing 
studies performed in both an optical engine and optical spray vessel by Musculuset al.[15] measured equivalence ratio fields after the end of injection, showing rapid reduction in equivalence ratio near the injector nozzle. Shortly after the end of the injection, within approximately $1 \mathrm{CAD}$ or 139 microseconds, the regions near the injector tip are leaner than regions further downstream. This characteristic of the distribution persists for the rest of the measured cycle, with more fuel-rich mixtures at greater distances from the injector.This rapid reduction in equivalence ratio near the injector is driven by advection and enhanced mixing that arises from the reduction of flow through the nozzle approaching the end of the injection. Changes in mixing, or entrainment, during rapid velocity variations at the nozzle have been measured in turbulent gas jets by several authors [16-19]. For diesel jets, Musculus and coworkers [20-22] showed how charge temperature and densityas well as the profile of end-ofinjection transient affect the evolution and propagation of large-scale structures downstream in the jet to increase entrainment. Recent experimental measurements of mixing in a single diesel jet have confirmed the "entrainment wave" during and after the end of injection[23]. A number of studies have connected this enhanced entrainment mechanism to the formation of overly-lean regions near the injector after the end of injection at LTC conditions [1, 14, 15, 24]. Although enhanced mixing is a critical feature of LTC conditions for avoiding fuel-rich regions that form soot, some regions can become over-mixed such that the local fuel concentrations are too low to sustain combustion.

One way to reduce UHC emissions from these overly-lean sources is with the use of closecoupled post injections [24-27]. Initial studies by Chartieret al. [25], Kociet al. [27], Anselmiet al. [26], and Skeen et al.[28] showed promising results for UHC reduction using a post injection at a limited range of conditions. Recent work by O'Connor and Musculus[24] has detailed the 
sensitivity of UHC reduction by a post injection, termed "post-injection efficacy," to a wide range of injection parameters. Post-injection efficacy was most sensitive to the duration of the post injection and the ignition delay of the mixture after the start of the post injection; postinjection efficacy was relatively insensitive to the main-injection duration as well as the dwell time between the end of the main injection and the beginning of the post injection. The goal of the current work is to better understand the mechanism by which post injections reduce leansource UHC emissions at LTC conditions.

\section{Experimental Overview}

\subsection{Optical Engine}

The optical engine is a modified version of a single-cylinder Cummins N-series direct-injection, heavy-duty diesel engine. The engine is equipped with a Bowditch piston with an open, rightcylindrical bowl and a flat fused-silica piston-crown window providing imaging access to the bowl, viewing from below. A 30-mm-wide curved window matching the contour of a portion of the piston bowlwall allows laser access into the bowl. Engine and fuel injector specifications are in Table 1 and a schematic of the engine and experiment is in Figure 1. Further details about this engine can be found elsewhere[11, 29].

Table 1. Engine and fuel system specifications.

\begin{tabular}{|l|l|}
\hline Engine base type & Cummins N-14, DI diesel \\
\hline Number of cylinders & 1 \\
\hline Cycle & 4 -stroke \\
\hline Number of intake valves & 2 \\
\hline Number of exhaust valves & $1^{\mathrm{a}}$ \\
\hline Combustion chamber & Quiescent, direct injection \\
\hline Swirl ratio & 0.5 (approx.) \\
\hline
\end{tabular}




\begin{tabular}{|l|l|}
\hline Bore & $139.7 \mathrm{~mm}[5.5 \mathrm{in}]$ \\
\hline Stroke & $152.4 \mathrm{~mm}[6.0 \mathrm{in}]$ \\
\hline Bowl width & $97.8 \mathrm{~mm}[3.85 \mathrm{in}]$ \\
\hline Displacement & 2.34 liters $\left[142 \mathrm{in}^{3}\right]$ \\
\hline Geometric compression ratio & $11.2: 1$ \\
\hline Replicated compression ratio & $16: 1$ \\
\hline Fuel Injector & Delphi DFI-1.5 (light duty) \\
\hline Fuel injector type & Common-rail, solenoid actuated \\
\hline Rail pressure & 1200 bar \\
\hline Cup (tip) type & Mini-sac \\
\hline Number of holes \& arrangement & 8, equally-spaced \\
\hline Spray pattern included angle & $156^{\circ}$ \\
\hline Nominal orifice diameter & $0.131 \mathrm{~mm}$ \\
\hline
\end{tabular}

an this optically accessible diesel engine, one of the two exhaust valves of the production cylinder head was replaced by a window and periscope (see Fig. 1).

A Delphi DFI 1.5 light-duty, solenoid-actuated common-rail injector with eight equally spaced 131-micron orifices was used for its fast response time and its ability to deliver consistent, closecoupled, short-duration post injections over a range of injection schedules. The fuel is $n$-heptane, which was selected for its low fluorescence upon illumination by ultraviolet (UV) laser-light, while retaining ignition properties typical of diesel fuel.

\subsection{Optical Engine Diagnostics}

Several diagnostics are used to investigate the origin of UHC emissions at LTC conditions, includingcylinder pressure measurements and three different optical diagnostics.Cylinder pressure is measured with an AVL QC34D piezoelectric pressure transducer and recorded every quarter crank angle degree. The apparent heat release rate is calculated from the measured cylinder pressure using standard techniques [30].

Two different optical diagnostic techniques are employed to gain insight into the origins of UHC emissions. These techniquesimageimportant species involved in ignition, formaldehyde $\left(\mathrm{CH}_{2} \mathrm{O}\right)$ and the hydroxyl radical $(\mathrm{OH})$, which provide information about the evolution of unburned fuel. 
Formaldehyde is produced during first-stage ignition and is consumed during second-stage, hightemperature ignition. After first-stage ignition, the evolution of formaldehyde mirrors that of the overall pool of unburned hydrocarbons $[14,15]$. Formaldehyde does not serve as a good marker for all unburned fuel, such as that from regions that have not achieved first-stage ignition (e.g., wall wetting and crevices), nor does it mark UHC in rich mixtures after second-stage ignition [1, 25]. While a small amount of $\mathrm{OH}$ is produced during first-stage ignition, its concentration rises by orders of magnitude at second-stage ignition [31], and hence provides an indication of second-stage ignition, complete combustion, and low local unburned fuel concentration.

Two laser-based techniques are used to measure these two important species, similar to previous studies conducted at LTC conditions in this engine $[14,25]$. The details of the two laser techniques are outlined in Table 2 .

Table 2. Diagnostic details of $\mathrm{CH}_{2} \mathrm{O}$-PLIF and $\mathrm{OH}$-PLIF techniques.

\begin{tabular}{|c|c|c|}
\hline & $\mathrm{CH}_{2} \mathrm{O}$-PLIF & OH-PLIF \\
\hline Laser & $\begin{array}{l}\text { Spectra-Physics Quanta-Ray single } \\
\text { cavity Nd:YAG }\end{array}$ & $\begin{array}{l}\text { - Spectra-Physics Quanta-Ray single } \\
\text { cavity Nd:YAG and } \\
\text { - Spectra-Physics OPO with BBO } \\
\text { doubling crystal }\end{array}$ \\
\hline Wavelength & $355 \mathrm{~nm}$ & $284 \mathrm{~nm}$ \\
\hline Energy/pulse & $80 \mathrm{~mJ} /$ pulse & $19 \mathrm{~mJ} /$ pulse \\
\hline Sheet width & $30 \mathrm{~mm}$ & $30 \mathrm{~mm}$ \\
\hline Sheet thickness & $1 \mathrm{~mm}$ & $1 \mathrm{~mm}$ \\
\hline Orientation & $12^{\circ}$ from firedeck & $12^{\circ}$ from firedeck \\
\hline Camera & Princeton Instruments PI-MAX3 & Princeton Instruments PI-MAX 3 \\
\hline Intensifier & HQf (GEN-III) & $\begin{array}{l}\text { Super-blue slow gate intensifier } \\
\text { (GEN-II) }\end{array}$ \\
\hline Resolution & $1024 \times 1024$ & $1024 \times 1024$ \\
\hline Gate & $50 \mathrm{~ns}$ & $410 \mathrm{~ns}$ \\
\hline Gain & $100 \%$ & $100 \%$ \\
\hline Lens & Nikkor glass f/2.5 & UV Nikkor f/4.5 \\
\hline Filters & $\begin{array}{l}\text { - Long-wave-pass, } 310 \mathrm{~nm} \\
\text { (beamsplitter) } \\
\text { - Long-wave-pass, } 385 \mathrm{~nm} \\
\text { - Blocked bandpass, } 320 \mathrm{~nm}, 40 \mathrm{~nm} \\
\text { FWHM }\end{array}$ & $\begin{array}{l}\text { - Short-wave pass, } 310 \mathrm{~nm} \\
\text { (beamsplitter) } \\
\text { - Blocked bandpass, } 310 \mathrm{~nm}, 65 \mathrm{~nm} \\
\text { FWHM } \\
\text { - Unblocked bandpass, } 310,15 \mathrm{~nm}\end{array}$ \\
\hline
\end{tabular}




\begin{tabular}{|l|l|l|}
\hline & & $\begin{array}{l}\text { FWHM } \\
\text { - Color-glass SWG305 }\end{array}$ \\
\hline
\end{tabular}

For both laser-induced fluorescence techniques, the laser-induced fluorescence data are limited to one frame per cycle. The OH-PLIF laser pulse and signal collection occurs 1 microsecond before those of the $\mathrm{CH}_{2} \mathrm{O}$-PLIF so that the two techniques are separate relative to fluorescence timescales (tens of nanoseconds), but virtually simultaneous relative to engine time scales (microseconds). As shown in Figure 1, the fluorescence emission is collected through the pistoncrown window and directed to the three cameras using two beamsplitters. A long-wave-pass beamsplitter with a cut-off near $385 \mathrm{~nm}$ directs UV light to the OH-PLIF ICCD camera. The remaining light is split by a $50 \%$ reflectance broadband beamsplitter between the $\mathrm{CH}_{2} \mathrm{O}$-PLIF ICCD camera and a third camera for high-speed natural-luminescence imaging.

\subsection{Engine Operating Conditions}

The engine is operated in a high-EGR $\left(12.6 \%\right.$ intake $\left.\mathrm{O}_{2}\right)$, late-injection LTC mode summarized in Table 2. LTC operation is generally limited to low-load conditions, so we operate the engine over the low-load range indicated in Table 3 where previous studies have shown relatively high UHC emissions for single-injection operation[24]. Other details about the engine operating conditions are also listed in Table 3.

Table 3. Engine operating conditions.

\begin{tabular}{|l|l|}
\hline Engine Speed & 1200 RPM \\
\hline Engine Load Range & $1-6$ bar gIMEP \\
\hline Intake $\mathrm{O}_{2}$ & $12.6 \%$ \\
\hline TDC Motored Density $^{\mathrm{b}}$ & $18 \mathrm{~kg} / \mathrm{m}^{3}$ \\
\hline TDC Motored Temperature $^{\mathrm{b}}$ & $837 \mathrm{~K}+/-4.2 \mathrm{~K}$ \\
\hline TDC Motored Pressure $^{\mathrm{b}}$ & $43.9+/-0.2 \mathrm{bar}$ \\
\hline BDC Pressure & $164 \mathrm{kPa}$ \\
\hline
\end{tabular}




\begin{tabular}{|l|l|}
\hline BDC Temperature & $78^{\circ} \mathrm{C}$ \\
\hline (16:1 Compression Ratio BDC Pressure) & $101 \mathrm{kPa}(\mathrm{abs})$ \\
\hline (16:1 Compression Ratio BDC Temperature) & $36^{\circ} \mathrm{C}$ \\
\hline
\end{tabular}

${ }^{a}$ gIMEP $=$ Gross Indicated Mean Effective Pressure, calculated using indicated work done during compression and expansion strokes only.

${ }^{\mathrm{b}}$ TDC conditions have been estimated using polytropic compression with a polytropic exponent of 1.359. The uncertainties in TDC conditions are calculated from propagating the uncertainty in the intake air temperature and pressure measurements through the polytropic calculation.

\subsection{Test Matrix}

The test matrix is provided in Table 4. Three timings for the start of solenoid energizing for the main injection (SSE1) have been tested, SSE1=349 CAD, $352 \mathrm{CAD}$, and $355 \mathrm{CAD}$, to observe the effect of thermal conditions on combustion efficiency and post-injection efficacy. The real start of injection (fuel emanating from the injector nozzles) occurs approximately 3 CAD after SSE1due to electromechanical and hydrodynamic delays inside the injector. At each SSE1, the duration of solenoid energizingfor the main injection (DSE1) is varied over the range indicated in Table 4 to achieve the load range in Table 3. Additionally, the duration of solenoid energizing for post-injection (DSE2) is swept at a given DSE1 to observe the effect of post-injection fuel quantity and penetration on UHC emissions reduction. The trade-offs in post-injection test matrix design have been previously described by O’Connor and Musculus[32].

Table 4. Engine operating test matrix with commanded injection timings and durations. Accuracy of the timings is +/- 0.2 CAD.

\begin{tabular}{|c|c|c|c|c|c|}
\hline$\% \mathrm{O}_{2}$ & SSE1 [CAD] & DSE1 [usec] & 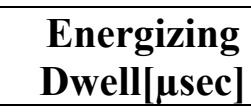 & DSE2 [ $\mu$ sec] & $\begin{array}{l}\text { Injected mass } \\
\text { per cycle [mg] }\end{array}$ \\
\hline 12.6 & 349 & $600-2400$ & & & $23.6-85.1$ \\
\hline 12.6 & 349 & 1000 & 210 & $200-800$ & $40.1-73.1$ \\
\hline 12.6 & 352 & $600-2400$ & & & $23.6-85.1$ \\
\hline 12.6 & 352 & 1000 & 210 & $200-800$ & $40.1-73.1$ \\
\hline 12.6 & 355 & $600-2400$ & & & $23.6-85.1$ \\
\hline 12.6 & 355 & 1000 & 210 & $200-800$ & $40.1-73.1$ \\
\hline
\end{tabular}


The solenoid energizing dwell between the end of the main injection and the beginning of the post injection is held constant at 210 microseconds during these tests. The solenoid energizing dwell is purposely kept short, or "close-coupled," to reduce losses in engine efficiency that occur with excessive combustion phasing retard. Although this is an important quantity for engine efficiency, previous work [24] has shown that variations in dwellfrom 70 to 420 microseconds have nearly the same post-injection efficacy on UHC emissions.

\subsection{Chemical kinetic modeling}

Chemical kinetic modeling is used to better understand data from the engine.These simulations are not an effort to realistically model in-cylinder processes, but instead to demonstrate how various parametric variations affect ignition delay in canonical scenarios and to aid interpretation of experimental data. Two different reactor models, a homogeneous reactor model and a twostage Lagrangian jet-mixing model, are used to determine the sensitivity of key quantities, such as ignition delay time and ignition limits, to thermal and mixing parameters independently.While higher fidelity combustion models that capture both fluid mechanic and chemical processes exist and could be used in conjunction with an experiment like the one described here, the use of canonical models such as a homogeneous reactor or Lagrangian jet flow allow us to decouple simultaneous processes and develop a better parametric understanding of in-cylinder effects. In particular, mixture ignition delay, which we have found is a key parameter driving unburned hydrocarbon emissions at LTC conditions[24], spans several different events.

Using chemical modeling, we wish to extract the effects of mixing versus chemical induction on the efficacy of multiple-injection schedules for UHC reduction at LTC conditions. To better 
understand these effects separately, we use two low-order reactor models with detailed chemistry. Both reactor models use the Lawrence Livermore detailed $n$-heptane mechanism version $3.1[33,34]$. More details regarding the validation of this mechanism as well as the range of validity are discussed in the Supplemental Material; the ranges of validation are shown with the simulation results. The homogeneous reactor modelonly accounts for the chemical induction portion as it is assumed that the reactor is perfectly mixed. The Two-Stage Lagrangian(TSL) jet modelaccounts for both the mixing and chemical induction portion of ignition delay. The use of these two models allow us to understand the role of chemical processes versus mixing processes in these flow fields and can help to explain the experimental data we collect from the engine. Details of the two models are provided in the Supplemental Material.

\section{Results}

Results of both the experimental and chemical modeling effort are presented in this section. We first discuss the results of the single-injection experiments to provide a baseline for the second part of this section that discusses the effect of the post injection.

\subsection{Single-Injection Experimental Results}

Three single-injection timings at a range of injection durations show the effect of the start of injection and the thermal conditionsof the in-cylinder ambient gases on engine-out UHC emissions and ignition characteristics of the mixtures. The thermal conditions of the in-cylinder ambient gases are somewhat different over the duration of each injection and subsequent combustion event for these three cases, as can be inferred from the pressure data in Figure 1 of the Supplemental Material. Given that the temperature at bottom-dead center (BDC) of the piston's stroke is held constant (Table 3), the compressed temperature of the ambient gases is 
affected by the cylinder pressure. Conditions with higher cylinder pressure at a given crank angle position have a higher in-cylinder temperature. In Figure 1 of the Supplemental Material, circles indicate the actual beginning of injection and squares indicate the end of injection. These results show that both the peak pressure as well as the variation in temperature and pressure during the injection and subsequent combustion varies for the three injection timings.

Despite these differences in thermodynamic path during the injection, the measured ignitiondelay time of the mixture in all three cases is very similar: approximately 9.1-9.6 CAD or 12651334 microseconds. The ignition delay time is calculated for the main injection by taking the difference between the start of the main injection and the start of second-stage combustion. The start of second-stage combustion is calculated from the zero-crossing of the apparent heat release rate (AHRR) after first-stage heat release. Recent experiments in this engine [35] have shown that the zero-crossing of the AHRR profile correlates very well with the first appearance of hightemperature chemiluminescence emission, indicating that AHRR is a good metric for ignition. The start of injection, when fuel starts to emerge from the injector orifices,is measured using high-speed video of Mie-scattering from the liquid jets.

The thermodynamic paths traversed by the in-cylinder gases during the injection have significant implications for how much of the mixture reachessecond-stage ignition, and hence, UHC emissions. A detailed discussion of emissions trends can be found in Figure 8 in O'Connor and Musculus[24]. While the UHC trends at all three timings have a similar shape, the absolute engine-out UHC is different between these three conditions. The earliest timing, SSE1=349 CAD, produces the lowest UHC emissions, while the latest timing, SSE1 $=355 \mathrm{CAD}$, produces the highest UHC emissions over this low-load range. To understand why these engine-out emissions results vary greatly between injection timings despite having similar ignition delay 
times, we turn to the optical results at an injection duration of DSE1=1000 microseconds.Figure 2 shows a time series of instantaneous $\mathrm{OH}-\mathrm{PLIF} / \mathrm{CH}_{2} \mathrm{O}-\mathrm{PLIF}$ images for the three injection timings, one in each column, starting at second-stage ignition and running through much of the combustion process.

In each of the three timings in Figure 2, second-stage combustion begins in mixtures near the bowl wall after an ignition delay of approximately 9-10 CAD and an ignition dwell of approximately 2-3 CAD, as shown by the OH-PLIF signal in that region. At this time, the mixture along the jet centerline has undergone first-stage ignition, as indicated by the $\mathrm{CH}_{2} \mathrm{O}$ PLIF signal, and so still contains a large fraction of UHC. At 6 AEI, more of the mixtures at the bowl wall and along the jet centerline undergo second-stage ignition. The extent to which second-stage ignition is able to recess toward the injector is different for the three injection timings.Similar combustion recession processes have been seen in other studies[25, 28, 36-38].

It is clearly evident from the more widespread $\mathrm{OH}$ signalin the early injection-timing images in Figure 2that a greater extent of the mixture in the SSE1 $=349$ CAD case reaches second-stage ignition than in the two later timings. This is consistent with the engine-out UHC emissions results that show that early-timing cases have the least UHC emissions. While the fluid-mechanic processes associated with the in-cylinder flows and the sprays at each injection timing are relatively similar, the thermal conditions during injection and through combustion are different. These differing thermal conditions result in different functional dependencies of ignition delay time on mixture equivalence ratio, meaning that different portions of the mixture will ignite at different times relative to the start of injection at each condition. 
Data from the homogeneous reactor and TSL models in Chemkin yield further understanding of the role of different thermal conditions on ignition delay times and the extent of complete combustion. Figure 3 shows the ignition delay time results of both the homogeneous reactor simulation and the TSL model, and also includes the ignition delay times measured in the engine tests.For both the reactor simulations, the ignition delay is denoted as the time when the mixture temperature reaches $1200 \mathrm{~K}$ [39]. For the homogeneous reactor simulation, shown in dashed lines, the ignition delay time is plotted over a range of mixture equivalence ratios, 0.1 to 5 , for the three injection timings and pressure histories.Ignition delay times from the TSL model are not a function of any pre-defined equivalence ratio as the fuel/air mixture varies throughout the duration of the simulation; as such, the TSL results are plotted as the dot-dashed horizontal line in the plot. Similarly, the ignition delay time measurements from the engine are plotted as the solid horizontal line.

The results in Figure 3 are an encouraging sign that the simulations are capturing important effects in the ignition of these fuel/air mixtures because the ignition delay times are similar between the simulations and engine data. The standard deviation of the measured (engine) ignition delay times across 70 cycles is between 0.2 and 0.3 microseconds, or $2-3 \%$ of the ignition delay time depending on case. The measured ignition delay times are located near the minimum ignition delay times from the homogeneous reactor simulation, which does not include the effect of mixing. This indicates that there may be a range of mixture equivalence ratios that ignite first, causing significant pressure rise in the cylinder and driving the measurement of ignition delay time in the engine. Later, mixtures with equivalence ratios above and below these "most ignitable mixtures" ignite, as can be seen in the OH-PLIF measurements in Figure 2. The results from the TSL model, which uses a constant pressure that was measured at the beginning 
of the injection, over-predict the ignition delay times significantly. This may be an indication that the increasing pressure and temperature, due to cylinder motion,during the ignition delay period play a key role in driving the ignition delay times. However, the entrainment model in TSL, which assumes a constant entrainment rate and uses a single Lagrangian time-mixing history for all mixtures, may not be accurate enough to properlysimulate the mixing processes relevant to ignition.

The homogeneous-reactor ignition-delay calculations in Figure 3also help to explain the similarity in the measuredignition delay time of the three single-injection timings,as well as the differences in the fraction of the in-cylinder mixture that reaches second-stage ignition after each initial ignition event.In the homogeneous reactor simulations, the mixtures with the shortest ignition delays - mixtures with equivalence ratios between roughly 1.2 and 2 - have very similar ignition delay times for all three injection timings and pressure histories. However, at equivalence ratios away from this range, the ignition delay times diverge significantly between the three cases. This is an indication of why second-stage ignition proceeds at very different rates throughout the combustion chamber at these three timings. OH-PLIF images of the second-stage ignition progression for the SSE1=349 CAD timing show that second-stage ignition spreads more quickly throughout the combustion chamber than the other two cases. This is likely due to the fact that more of the mixture in the early-injection cases has an equivalence ratio with shorter ignition delay times than the mixtures in the later injection timing cases.

Additionally, both the lean and rich ignition limits for each injection timing are different. For example, the lean ignition limit for the $\mathrm{SSE} 1=349 \mathrm{CAD}$ condition is 0.5 , while the lean ignition limit for the SSE1 $=355 \mathrm{CAD}$ condition is 0.6 . This difference implies that there will be a slightly greater quantity of lean mixtures that are able to ignite at the early-timing condition but not at the 
late-timing condition. This is also true on the rich side, where the difference in the rich-ignition limits between the three conditions is even larger.In addition to differences in the amount of mixture within and outside the ignition limits, these differences in the extent of the ignition limits may also drive the differences in the fraction of the mixture that reaches complete combustion between the three injection timings.

These differences in main-injection ignition and combustion development serve as an "initial condition" for the post injection, which is added to help induce second-stage ignition in a greater portion of the fuel/air mixture. There are differences in both thermal conditions and local mixture composition when the injector solenoid is energized 1.5 CAD (or 210 microseconds) after the end of solenoid energizing for the main injection.

\subsection{Post-Injection Experimental Results}

Sensitivity studies of post-injection efficacy to a variety of injection and chemical parameters, described in Ref. [24], showed that post-injection efficacy is most sensitive to post-injection duration and post-injection ignition delay. Measurements of engine-out UHC indicate that post injections can reduce UHC emissions over a range of post-injection durations and at all three main-injection timings[24]. While UHC reduction trends with the addition of a post injection are similar between the three injection timings, the post-injection efficacy is greater for the early injection timing than it is for the late injection timing. At the SSE1=349 CAD timing, the maximum engine-out UHC reduction with a post injection is $34 \%$ as compared to a single injection at the same load, as opposed to theSSE1 $=355 \mathrm{CAD}$ timing where the maximum engineout UHC reduction with a post injection isonly 14\%, as shown in Figure 12 of Ref. [24].At all main-injection timings, the maximum UHC reduction is achieved using a post injection with a duration of solenoid energizing (DSE2) between 350 and 450 microseconds. This indicates that 
each post injection is acting to reduce UHC, presumably by reducing lean-source UHC, but that certain post-injection durations are more effective at reducing UHC than others.

Post-injection efficacy is also driven by the thermal conditions during the post injection and subsequent combustion. As shown in Figure 1 of the Supplemental Material, the post injection begins just as the second-stage ignition of the main injection begins and lasts through much of the pressure rise due to combustion of the main-injection mixture; in all cases, the post injection is injected during a pressure rise. The magnitude of the pressure rise, however, is significantly different between the three cases.Engine data show significant differences in the post-injection ignition delay, or the ignition delay of the mixture after the start of the post injection, at these three main-injection timings. The post-injection ignition delay is calculated as the time between the start of the post injection fueling event and the start of combustion of the post injection. The start of the post-injection combustion is calculated by taking the difference between the AHRR of a condition with a post injection and one with a single injection only; the start of combustion of the post injection is the first zero crossing in the AHRR difference. The post-injection ignition delay is $3.4 \mathrm{CAD}$ (473 microseconds) at the SSE1 $=349 \mathrm{CAD}$ condition, 3.6 CAD (500 microseconds) at the SSE1 $=352 \mathrm{CAD}$ condition, and 5.5 CAD (765 microseconds) at the SSE1 $=349$ CAD condition .

Differences in post-injection efficacyand ignition delay, and the effect of these different thermal conditions on post-injection combustion can be better understood through analysis of the optical data at these three conditions. Figure 4 shows a comparison of simultaneous $\mathrm{OH}-\mathrm{PLIF} / \mathrm{CH}_{2} \mathrm{O}-$ PLIF images at the SSE1 $=349$ CAD (left), SSE $1=352$ CAD (center), and SSE $1=355$ CAD (right) timings after the end of the post injection. 
The same initial stages of main-injection ignition are visible in the main- plus post-injection conditions in Figure 4 as they are in the single-injection conditions fromFigure 2. Second-stage ignition of the main-injection mixture occurs near the bowl wall in the recirculation zone on either side of the jet centerline (right side of images). During this time, the post injection is still injecting and ends at approximately 1-2 CAD after the start of second-stage ignition of the maininjection mixture. The spatial extent of second-stage ignition grows near the bowl wall and begins to recess along the jet centerline toward the injector, consuming much of the mixture that has undergone first-stage ignition only, indicated by the $\mathrm{CH}_{2} \mathrm{O}$-PLIF signal in red along the jet column. The time series of images in Figure 4 ends at the end of the combustion recession process; later stages of combustion continue in a similar fashion as in the single-injection case.

The addition of a post-injection has both temporal and spatial repercussions on the progression of second-stage ignition. First, the addition of a post injection causes the combustion recession to start at earlier crank angles, and the post injections with the shortest ignition delay times cause recession to happen sooner than those with long ignition delay times. For example, the combustion recession in the SSE1 $=349 \mathrm{CAD}$ condition starts approximately $1 \mathrm{CAD}$ after the end of the post injection, whereas in the SSE1=355 CAD condition it starts approximately 4-5 CAD after the end of the post injection. Second, the post injection has a significant effect on the spatial extent of second-stage ignition. At the SSE1=349 CAD timing, the addition of a post injection causes the second-stage ignition process to recess all the way to the injector tip, at $371 \mathrm{CAD}$ in the left column of Figure 4, whereas the spatial extent of the combustion recession is not nearly as great at the other two timings. Finally, the late-cycle extent of second-stage combustion is much greater in the SSE1=349 CAD case with a short-ignition-delay post injection. 
A comparison of the furthest extent of second-stage combustion recession and late-cycle secondstage combustion in Figure 5 shows the marked differences between post injections with different ignition delay times and thermal conditions. The post injection, even as it is short and close-coupled to the main injection, has a significant effect on both the temporal and spatial behavior of second-stage ignition throughout the rest of the combustion processes.

Chemical modeling is used to calculate the ignition delay times of the post-injection mixture.Figure 6 shows the measured ignition delay times as well as the calculated ignition delay times from both the homogeneous reactor and two example solutions from the TSL model for post-injection mixtures at the three injection timings (see the Supplemental Material for a more complete description of the TSL cases). The standard deviation of the measured (engine) ignition delay times across 70 cycles is between 0.2 and 0.3 microseconds, or $5-7 \%$ of the post-injection ignition delay time, depending on case. The range of equivalence ratios shown here is much smaller than in the single-injection calculations because it is expected that the smaller amount of fuel and rapid mixing of the post injection will not result in mixtures with equivalence ratios above 2 for any significant amount of time.The TSL model results labeled with $\mathrm{N}_{2} / \mathrm{O}_{2}$ are results where the entrained gases are $\mathrm{N}_{2}(87.4 \%)$ and $\mathrm{O}_{2}(12.6 \%)$ at the adiabatic core temperature for each SOI condition. The TSL model results labeled with "Int"(short for "intermediates") are results where the entrained gases are species found after first-stage ignition, but where the equivalence ratio is too low to proceed to second-stage ignition. Details of both these cases are outlined in Table 3 and Table 4 in the Supplemental Material.

Across the whole equivalence ratio range, the ignition delays predicted by the homogenous reactor simulations are longer than the measurements; even the shortest predicted ignition delay times are up to two times longer than the measured post-injection ignition delay in the engine 
experiments. The predictions from the two TSL simulations are two to three times longer than the measured ignition delays.Theselarge differences between the measured post-injection ignition delay times and those from the two simulations relative to the better agreement for the main injection (Figure 3) suggest that the simulations do not capture the relevant processes occurring during post-injection ignition.

Although the homogeneous reactor simulations results, which include cylinder pressure variations, are closer to the measured results, the composition of the gases in the homogeneous reactor simulation may cause the disagreement in these data. In particular, the homogeneous reactor considers a mixture of fuel and air(only $\mathrm{N}_{2}$ and $\mathrm{O}_{2}$ ) at the adiabatic core temperature, instead of a mixture with intermediate species that may have been entrained into the postinjection mixture during the post-injection event. One other observation that merits discussion is the differences in the predicted ignition delay curves for the three cases in the homogeneous reactor simulations. For the post-injection ignition delay, the ignition delay curves for the three main-injection timings are well separated (Figure 6), whereas the predictions for the maininjection ignition delay are very similar in the equivalence ratio range from 1.2 to 2 (Figure 3). The difference in predicted post-injection ignition delay aligns well with the observations of second-stage ignition characteristics in the engine data. First, the SSE1=349 CAD timing mixtures have shorter ignition delays than the SSE1 $=355 \mathrm{CAD}$ mixtures for each equivalence ratio, which matches with the measured ignition delay time trends in the engine. Additionally, the lean ignition limits for each injection timing align with the spatial extent of the second-stage ignition measured in the combined OH-PLIF/ $\mathrm{CH}_{2} \mathrm{O}-\mathrm{PLIF}$ results as compared to those of Musculuset al. [15].The lean limit of the SSE1 $=355 \mathrm{CAD}$ mixture is 0.75 as compared to the SSE1=349 CAD mixture with a lean ignition limit of 0.55 . This difference helps to explain the 
fact that a larger portion of the lean mixture near the injector underwent second-stage ignition at the SSE1=349 CAD timing.

In summary, the engine-out UHC measurements indicate that the addition of a short, closecoupled post injection can help to reduce engine-out UHC emissions by up to $44 \%$ in the best case.Companion PLIF data measuring the spatial and temporal evolution of both first-stage and second-stage ignition of the fuel/air mixture indicate that adding a post injection allows lean mixtures near the injector to reach second-stage ignition, whereas mixtures in this region were halted after first-stage ignition in the single-injection case. However, these measurements don't directly capture the mechanism by which the post injection reduces UHC from overly-lean sources near the injector. In the next section, we discuss possible mechanisms by which the post injection can reduce lean-source UHC and what additional experiments may be needed to further understand this process.

\section{Discussion}

There are several possible mechanisms by which the addition of a post injection could enhance oxidation of lean-source unburned hydrocarbons. The first possible mechanism is a purely thermal mechanism where we define the thermal state as the bulk pressure and temperature of the in-cylinder mixture. Here, we positthat the additional pressure rise resulting from the combustion of the post injection compresses the lean mixtures near the injector, thereby raising the bulk cylinder temperature and enhancing ignition chemistry overall; this does not account for local variations in temperature, which will occur and cannot accurately be modeled with the well-stirred reactor in Chemkin, but considers the bulk thermal state driven by the pressure in the cylinder, which can be captured in Chemkin. To investigate the changes that the pressure rise 
and resulting temperature rise from the post-injection combustion have on the second-stage ignition of the main-injection mixture, additional chemical modeling with the homogeneous reactor model was performed. These simulationsstart at the beginning of the main injection with the same equivalence ratio range (0.1-5) and initial mixture temperatures as in the singleinjection simulations ofFigure 3. However, the pressure-time history applied to the homogeneous reactor is that of a main- plus post-injection condition. In this way, changes in the ignition delay times and ignition limits of the main-injection mixture due to post-injection combustion are assessed considering only the post-injection pressure rise, without the addition of post injection fuel to the mixture. Figure 7 shows a comparison of the ignition limits of a single-injection mixture with the single-injection pressure history (solid) and main- plus post-injection pressure history (dashed).

The pressure and temperature history in the reactor affects the ignition delay times of the rich mixtures more than it does the ignition delay time of the lean mixtures. The lean ignition limitsare not altered significantly by the increased pressure and bulk temperature from the postinjection combustion at any of the main-injection timings. The rich ignition limits are extended at all main-injection timings and ignition delay times at equivalence ratios between 3.5 and 5 decrease with the main- plus post-injection pressure trace. However, these changes to the richignition limits and ignition delay times would not affect the second-stage ignition of the lean mixtures near the injector, indicating that this thermal mechanism is not likely responsible for much enhancement of second-stage ignition near the injector.

Furthermore, the comparison of the main- plus post-injection conditions with the single-injection conditions at the same load(not the same SSE1), as shown in Table 5,indicates that the thermal mechanism cannot be solely responsible for lean-source UHC reduction. 


\section{Table 5. Comparison of load and engine-out UHC levels for main-plus post-injection}

conditions and single-injection conditions at similar loads.

\begin{tabular}{|c|c|c|c|c|c|c|}
\hline Condition & $\begin{array}{c}\text { SSE1 } \\
{[\mathbf{C A D}]}\end{array}$ & $\begin{array}{c}\text { DSE1 } \\
{[\boldsymbol{\mu} \mathbf{s}]}\end{array}$ & $\begin{array}{c}\text { SSE2 } \\
{[\mathbf{C A D}]}\end{array}$ & $\begin{array}{c}\text { DSE2 } \\
{[\boldsymbol{\mu s}]}\end{array}$ & $\begin{array}{c}\text { Load } \\
{[\mathbf{k P a}]}\end{array}$ & $\begin{array}{c}\text { UHC } \\
{\left[\mathbf{p p m} \mathbf{C}_{\mathbf{1}}\right]}\end{array}$ \\
\hline Main plus post & 349 & 1000 & 360.5 & 400 & 371 & 19 \\
\hline Main plus post & 352 & 1000 & 363.5 & 400 & 371 & 25.9 \\
\hline Main plus post & 355 & 1000 & 366.5 & 400 & 352.5 & 46 \\
\hline Single & 349 & 1400 & & & 381 & 29.8 \\
\hline Single & 352 & 1400 & & & 381 & 35.3 \\
\hline Single & 355 & 1400 & & & 368.8 & 51.9 \\
\hline
\end{tabular}

The engine-out UHC is much higher with the single injection, as shown in Table 5, than with the addition of a post injection at the same load. These data indicate that UHC reduction resulting from the addition of the post injection cannot solely be a thermal effect from local compressionheating due to combustion pressure rise, and that there is some fluid-mechanic process and interaction between the post injection and the main-injection mixture that is controlling the UHC reduction.

Another proposed mechanism for UHC reduction with a post injection is that fluid mechanic effectsassociated with fuel from the post jet mixing with the surrounding gasesallow a larger portion of the lean mixture near the injector to reach second-stage ignition. Previous studies [24, 25] have proposed that post injections could act to enrich the region near the injector, raising the equivalence ratio to a point inside the ignition limits and allowing the near-injector mixture to reach second-stage ignition. The mechanism by which this region is enriched by the post injection was not directly measured due to the lack of direct velocity or mixing measurements at reacting conditions. A number of studies in the post-injection literature[40-43]hypothesize that the fuel from the post injection directly adds to the lean mixture near the injector that has reached 
first-stage, but not second-stage, ignition, allowing it to reach second-stage ignition. However, the mechanism of a post-injection directly adding fuel to the mixtures that remain after the main injection does not align with fluid-mechanic processes observed in starting jets.Studies of impulsively started turbulent jets have shown that a vortex forms at the head of the jet and displaces fluid ahead of it as it penetrates downstream[44-46]. Entrainmentoccurs not at the head, but rather behind the head of the jet in large sweeps and along the length of the jet. These processes in a gas/single-phase jet can likely be applied to a diesel jet [20, 47], informing our interpretation of the mechanisms occurring during post injections.

These observations of starting jets would indicate that while some smaller-scale turbulent entrainment takes place along the periphery of the post jet boundary, the head of the post jet pushes the partially-reacted residual main-injection mixture downstream and to the side as the post jet penetrates towards the bowl wall.Before the start of the post injection, in the dwell between the end of the main injection and the beginning of the post injection, relatively stagnant fuel/air mixture in the jet core diffuses away from the jet centerline, as shown in the mixing measurements in Ref. [15]. As a result, partially-reacted mixture from the main injection will be likely entrained into the post jet along with a certain amount of charge gases from outside the boundary of the main-injection mixture. This new mixture in the post-jet - a mix of fresh postinjection fuel, main-injection mixture that has undergone first-stage ignition, and charge gases may be within the ignition limits and will likely have a shorter ignition delay time than the maininjection mixture that was not able to ignite. This more reactive mixture may largely replace the unburned, overly-lean mixture near the nozzle, allowing second-stage ignition closer to the injector, thereby reducing the engine-out UHC. Additionally, the overly-lean mixture pushed ahead of the starting jet may be displaced intoand mixed inregions with more reactive mixtures, 
allowing the UHC in this partially-reacted mixture to burn to completion.Recent results by Skeen et al.[28] from a split-injection schedule in a constant-volume combustion chamber show very similar trends.

The effect of entrainment of different surroundings by the post injection is also investigated using the TSL model in Chemkin. Unfortunately, this model does not capture the pressure rise during the ignition period, which we have shown in several instances in this work may be an important driver of ignition delay time. Despite this, the TSL simulation results in Figure 8 show the sensitivity of the ignition delay to surrounding gas composition.

The three sets of simulation results at three injection timings in Figure 8show the sensitivity of the post-injection ignition delay to entrained mixture composition and. Three mixture compositions where considered: the intake charge composition of $12.6 \% \mathrm{O}_{2}$ and $87.4 \% \mathrm{~N}_{2}$ by volume (denoted here by " $\mathrm{N}_{2} / \mathrm{O}_{2}$ "), the product composition of second-stage ignition of a single injection with an equivalence ratio at the lean ignition limit (denoted here by "Products"), and the products of first-stage ignition of a single injection with an equivalence ratio of 0.3 (denoted here by "Int" for intermediates). The temperature was considered to be the adiabatic core temperature $\left(\mathrm{T}_{\mathrm{AC}}\right)$ in order to compare the effect of surrounding gas composition directly to the initial intake conditions with $12.6 \% \mathrm{O}_{2}$ and $87.4 \% \mathrm{~N}_{2}$ by volume at $\mathrm{T}_{\mathrm{ac}}$. These conditions are outlined in Table 3 and Table 4 in the Supplemental Material.

Looking first at the results with the $\mathrm{N}_{2} / \mathrm{O}_{2}$ surrounding gases, a first point of interest is how the ignition delay times of the post injection with the entrained $\mathrm{N}_{2} / \mathrm{O}_{2}$ mixture at the adiabatic core temperature $\left(\mathrm{T}_{\mathrm{AC}}\right)$ calculated in the TSL model compare with those of the homogeneous reactor model, shown in Figure 6. The ignition delay times from the homogeneous reactor model are 
about half the time as those calculated in the TSL model for each injection timing case; this result indicates that the pressure variation may be more critical to capturing the true ignition delay than including the effects of mixing.The next simulation, where lean-mixture second-stage ignition products are used as the surrounding gas composition, shows that adding high heatcapacity products like $\mathrm{CO}_{2}$ and $\mathrm{H}_{2} \mathrm{O}$ has a moderate effect on ignition delay times, making the ignition process slower with the addition of diluents.

Finally, the addition of first-stage ignition products (see Table 4 in the Supplemental Material for compositional details) to the surrounding gases has some effect on the ignition delay time. At the adiabatic core temperature, addedintermediates reduce the ignition delay time, presumably as a result of the presence of more highly reactive species like $\mathrm{H}_{2} \mathrm{O}_{2}$. The addition of further intermediate species (including some radicals) with molar concentrations less than $10^{-3}$ but greater than $10^{-4}$ showed little change in ignition delay time, as is shown by the green circle in Figure 8 at the SSE1=352 CAD timing for the "Int" composition at the adiabatic core temperature.

\section{Conclusions}

The results of this investigation have shown that close-coupled post injections can be used to reduce engine-out UHC emissions by reducing the lean-source UHC at low-load, LTC conditions in a heavy-duty diesel engine. The major conclusions from this study are as follows.

1. Engine-out UHC emissions at low-load, LTC conditions can originate from overly-lean mixtures near the injector tip resulting from enhanced mixing at the end of injection and dilution of the fuel/air mixture in this region to a point beyond the lean ignition limit. While the overall ignition delay of the mixtures injected at three different times in this 
studyarenearly the same, 9.1-9.6 CAD, the spatial extent of second-stage ignition is very different, resulting in much higher engine-out UHC emissions for the latest injection timing than the earliest. The reason for this is explored using chemical kinetic modeling to calculate ignition delay times over a range of equivalence ratios from 0.1 to 5 , and it is found that a large range of mixtures, equivalence ratios from 1.2 to 2.5 , have similar ignition delay times, but that both the ignition delay times outside this range and the lean and rich ignition limits are different enough between the three cases to result in very different second-stage ignition distributions and engine-out UHC levels.

2. Differences in post-injection efficacy can be resolved by understanding what drives the post-injection ignition delay. The most effective post injection (SSE1=349 CAD) has an ignition delay of 3.4 CAD, whereas the least effective post injection (SSE1=355 CAD) has an ignition delay of 5.5 CAD. These differences in post-injection ignition delay are reflected in chemical kinetic simulation of the post-injection mixture and are driven by differences in pressure and temperature conditions during and after the post injection. The addition of intermediate species from the first-stage ignition of the main injection also reduced post-injection ignition delay time and may be an important mechanism for shortening the ignition delay of the post-injection mixture.

3. The mechanism by which post injections reduce UHC emissions is not solely a thermal mechanism, but there must also be some fluid interaction between the post jet and the main-injection mixture. A proposed mechanism describes the post jet pushing the maininjection mixture near the injector downstream, simultaneously entraining some partiallyreacted main-injection mixture in that region, and reaching second-stage combustion in 
greater quantities due to the higher equivalence ratio and more favorable thermal environment.

\section{Acknowledgements}

The optical engine experiments were performed at the Combustion Research Facility, Sandia National Laboratories, Livermore, CA. Support for this research was provided by the U.S. Department of Energy, Office of Vehicle Technologies. Sandia is a multi-program laboratory operated by Sandia Corporation, a Lockheed Martin Company for the United State Department of Energy's National Nuclear Security Administration under contract DE-AC04-94AL85000. The injector was provided by Delphi Diesel Systems, and the authors would like to thank Delphi and Philip Dingle for their support of this system. The authors gratefully acknowledge the contributions of Keith Penney and Dave Cicone for their assistance in maintaining the lasers and research engine used in this study, and Dipankar Sahoo for assistance with the UHC analyzer.

\section{References}

1. Musculus, M.P.B., P.C. Miles, L.M. Pickett, (2013) "Conceptual models for partially premixed low-temperature diesel combustion" Prog. Energy Combust. Sci., 39(2-3):246283

2. Han, M., D.N. Assanis, S.V. Bohac, (2009) "Sources of hydrocarbon emissions from low-temperature premixed compression ignition combustion from a common rail direct injection diesel engine" Combust. Sci. Technol., 181(3):496-517

3. Koci, C.P., Y. Ra, R. Krieger, M. Andrie, D.E. Foster, R.M. Siewert, R.P. Durrett, I. Ekoto, P.C. Miles, (2009) "Detailed unburned hydrocarbon investigations in a highlydilute diesel low temperature combustion regime" SAE Technical Paper SAE Int. J. Engines, 2(1):858-879

4. Kim, D., I. Ekoto, W.F. Colban, P.C. Miles, (2008) "In-cylinder CO and UHC imaging in a light-duty diesel engine during PPCI low-temperature combustion" SAE Technical Paper SAE Int. J. Fuels Lubr., 1(1):933-956

5. Murata, Y., J. Kusaka, M. Odaka, Y. Daisho, D. Kawano, H. Suzuki, H. Ishii, Y. Goto, (2006) "Achievement of Medium Engine Speed and Load Premixed Diesel Combustion with Variable Valve Timing" 
6. Kimura, S., O. Aoki, Y. Kitahara, E. Aiyoshizawa, (2001) "Ultra-clean combustion technology combining a low-temperature and premixed combustion concept for meeting future emission standards" SAE Technical Paper SAE Trans., 110(4):239-248

7. Musculus, M.P.B., (2006) "Multiple Simultaneous Optical Diagnostic Imaging of EarlyInjection Low-Temperature Combustion in a Heavy-Duty Diesel Engine" SAE Technical Paper

8. Singh, S., M.P.B. Musculus, R.D. Reitz, (2009) "Mixing and flame structures inferred from OH-PLIF for conventional and low-temperature diesel engine combustion" Combust. Flame, 156(10):1898-1908

9. de Ojeda, W., P. Zoldak, R. Espinosa, R. Kumar, (2008) "Development of a Fuel Injection Strategy for Diesel LTC" SAE Technical Paper

10. Lewander, M., K. Ekholm, B. Johansson, P. Tunestål, N. Milovanovic, N. Keeler, T. Harcombe, P. Bergstrand, (2008) "Investigation of the Combustion Characteristics with Focus on Partially Premixed Combustion in a Heavy Duty Engine" SAE Int. J. Fuels Lubr., 1(1): 1063-1074

11. Dec, J.E., (1997) "A conceptual model of DI diesel combustion based on laser-sheet imaging" SAE Technical Paper SAE Trans., 106(3):1319-1348

12. Kanda, T., T. Hakozaki, T. Uchimoto, J. Hatano, N. Kitayama, H. Sono, (2006) "PCCI operation with fuel injection timing set close to TDC" SAE Technical Paper

13. Miles, P., D. Choi, L. Pickett, I. Singh, N. Henein, B. RempelEwert, H. Yun, R. Reitz, (2004) "Rate-limiting processes in late-injection, low-temperature diesel combustion regimes" Thermo- and Fluid-Dynamic Processes in Diesel Engines: THIESEL 2004, Valencia, Spain

14. Lachaux, T. and M.P.B. Musculus, (2007) "In-cylinder unburned hydrocarbon visualization during low-temperature compression-ignition engine combustion using formaldehyde PLIF" Proc. Combust. Inst., 31(2):2921-2929

15. Musculus, M.P.B., T. Lachaux, L.M. Pickett, C.A. Idicheria, (2007) "End-of-injection over-mixing and unburned hydrocarbon emissions in low-temperature-combustion diesel engines" SAE Technical Paper SAE Trans., 116(3):515-541

16. Borée, J., N. Atassi, G. Charnay, (1996) "Phase averaged velocity field in an axisymmetric jet subject to a sudden velocity decrease" Experiments in fluids, 21(6):447456

17. Borée, J., N. Atassi, G. Charnay, L. Taubert, (1997) "Measurements and image analysis of the turbulent field in an axisymmetric jet subject to a sudden velocity decrease" Experimental thermal and fluid science, 14(1):45-51

18. Johari, H. and R. Paduano, (1997) "Dilution and mixing in an unsteady jet" Experiments in fluids, 23(4):272-280

19. Zhang, Q. and H. Johari, (1996) "Effects of acceleration on turbulent jets" Physics of Fluids, 8:2185

20. Musculus, M.P.B. and K. Kattke, (2009) "Entrainment waves in diesel jets" SAE Technical Paper SAE Int. J. Engines, 2(1):1170-1193

21. Hu, B., M. Musculus, J. Oefelein, (2010) "Large Eddy Simulation of a Transient Air Jet with Emphasis on Entrainment during Deceleration" SAE Technical Paper

22. Hu, B., M.P.B. Musculus, J.C. Oefelein, (2012) "The influence of large-scale structures on entrainment in a decelerating transient turbulent jet revealed by large eddy simulation" Phys. Fluids, 24:045106 
23. Eagle, W.E., M.P. Musculus, L.-M. Malbec, G. Bruneaux, (2014) "Measuring transient entrainment rates of a confined vaporizing diesel jet" ILASS Americas 26th Annual Conference on Liquid Atomization and Spray Systems, Protland, OR

24. O'Connor, J. and M. Musculus, (2013) "Optical investigation of the reduction of unburned hydrocarbons using close-coupled post injections at LTC conditions in a heavyduty diesel engine" SAE Technical Paper SAE Int. J. Eng., 6(1)

25. Chartier, C., Ö. Andersson, B. Johansson, M. Musculus, M. Bobba, (2011) "Effects of post-injection strategies on near-injector over-lean mixtures and unburned hydrocarbon emission in a heavy-duty optical diesel engine" SAE Technical Paper SAE Int. J. Engines, 4(1): 1978-1992

26. Anselmi, P., J. Kashdan, G. Bression, E. Ferrero-Lesur, B. Thirouard, B. Walter, (2010) "Improving emissions, noise and fuel economy trade-off by using multiple injection strategies in diesel low temperature combustion (LTC) mode" SAE Technical Paper

27. Koci, C.P., Y. Ra, R. Krieger, M. Andrie, D.E. Foster, R.M. Siewert, R.P. Durrett, (2009) "Multiple-Event Fuel Injection Investigations in a Highly-Dilute Diesel Low Temperature Combustion Regime" SAE Int. J. Engines, 2(1):837-857

28. Skeen, S., J. Manin, L.M. Pickett, (2015) "Visualization of Ignition Processes in HighPressure Sprays with Multiple Injections of n-Dodecane" SAE Int. J. Engines, 8(2):696715

29. Espey, C. and J.E. Dec, (1993) "Diesel engine combustion studies in a newly designed optical-access engine using high-speed visualization and 2-D laser imaging" SAE Technical Paper SAE Trans., 99(4):703-723

30. Heywood, J.B., (1988) Internal combustion engine fundamentals, McGraw-Hill, New York, NY

31. Genzale, C.L., R.D. Reitz, M.P.B. Musculus, (2008) "Effects of piston bowl geometry on mixture development and late-injection low-temperature combustion in a heavy-duty diesel engine" SAE Technical Paper SAE Int. J. Engines, 1(1):913-937

32. O'Connor, J. and M. Musculus, (2014) "Effect of load on close-coupled post-injection efficacy for soot reduction in an optical heavy-duty diesel research engine" Journal of Engineering for Gas Turbines and Power, 136(10):101509-101509

33. Mehl, M., W.J. Pitz, M. Sjöberg, J.E. Dec, (2009) "Detailed Kinetic Modeling of LowTemperature Heat Release for PRF Fuels in an HCCI Engine"

34. Mehl, M., W.J. Pitz, C.K. Westbrook, H.J. Curran, (2011) "Kinetic modeling of gasoline surrogate components and mixtures under engine conditions" Proceedings of the Combustion Institute, 33(1):193-200

35. Malbec, L.-M., W.E. Eagle, M.P.B. Musculus, P. Schihl, (2015) "Influence of injection duration and ambient temperature on the ignition delay in a 2.34L optical diesel engine" 2015-01-1830 JSAE/SAE 2015 International Powertrains, Fuels \& Lubricants Meeting, Kyoto, Japan

36. Bobba, M.K., C.L. Genzale, M.P.B. Musculus, (2009) "Effect of ignition delay on incylinder soot characteristics of a heavy duty diesel engine operating at low temperature conditions" SAE Technical Paper SAE Int. J. Engines, 2(1):911-924

37. Koci, C., G. Martin, T. Bazyn, W. Morrison, K. Svensson, C. Gehrke, (2015) "The Influence of Diesel End-of-Injection Rate Shape on Combustion Recession" SAE Int. J. Engines, 8(2):647-659 
38. Knox, B.W., C.L. Genzale, L.M. Pickett, J.M. Garcia-Oliver, W. Vera-Tudela, (2015) "Combustion Recession after End of Injection in Diesel Sprays" SAE Int. J. Engines, 8(2):679-695

39. Westbrook, C.K., (2000) "Chemical kinetics of hydrocarbon ignition in practical combustion systems" Proc. Combust. Inst., 28(2):1563-1577

40. O'Connor, J. and M.P.B. Musculus, (2013) "Post injections for soot reduction in diesel engines: A review of current understanding" SAE Technical Paper SAE Int. J. Eng., 6(1)

41. Vanegas, A., H. Won, C. Felsch, M. Gauding, N. Peters, (2008) "Experimental investigation of the effect of multiple injections on pollutant formation in a common-rail DI diesel engine" SAE Technical Paper

42. Bobba, M., M.P.B. Musculus, W. Neel, (2010) "Effect of post injections on in-cylinder and exhaust soot for low-temperature combustion in a heavy-duty diesel engine" SAE Technical Paper SAE Int. J. Engines, 3(1):496-516

43. Hotta, Y., M. Inayoshi, K. Nakakita, K. Fujiwara, I. Sakata, (2005) "Achieving lower exhaust emissions and better performance in an HSDI diesel engine with multiple injection" SAE Technical Paper SAE Trans., 114(3):883-898

44. Krueger, P.S. and M. Gharib, (2003) "The significance of vortex ring formation to the impulse and thrust of a starting jet" Physics of Fluids, 15:1271

45. Johari, H., Q. Zhang, M. Rose, S. Bourque, (1997) "Impulsively started turbulent jets" AIAA journal, 35(4):657-662

46. Iglesias, I., M. Vera, A.L. Sánchez, A. Liñán, (2005) "Simulations of starting gas jets at low Mach numbers" Physics of Fluids, 17:038105

47. Naber, J.D. and D.L. Siebers, (1996) "Effects of gas density and vaporization on penetration and dispersion of diesel sprays" SAE Technical Paper SAE Trans., 105(3):82111 




Figure 1. Experimental setup of the single-cylinder engine, laser configuration, and threecamera optical system. The camera field-of-view is shown in the upper right. 


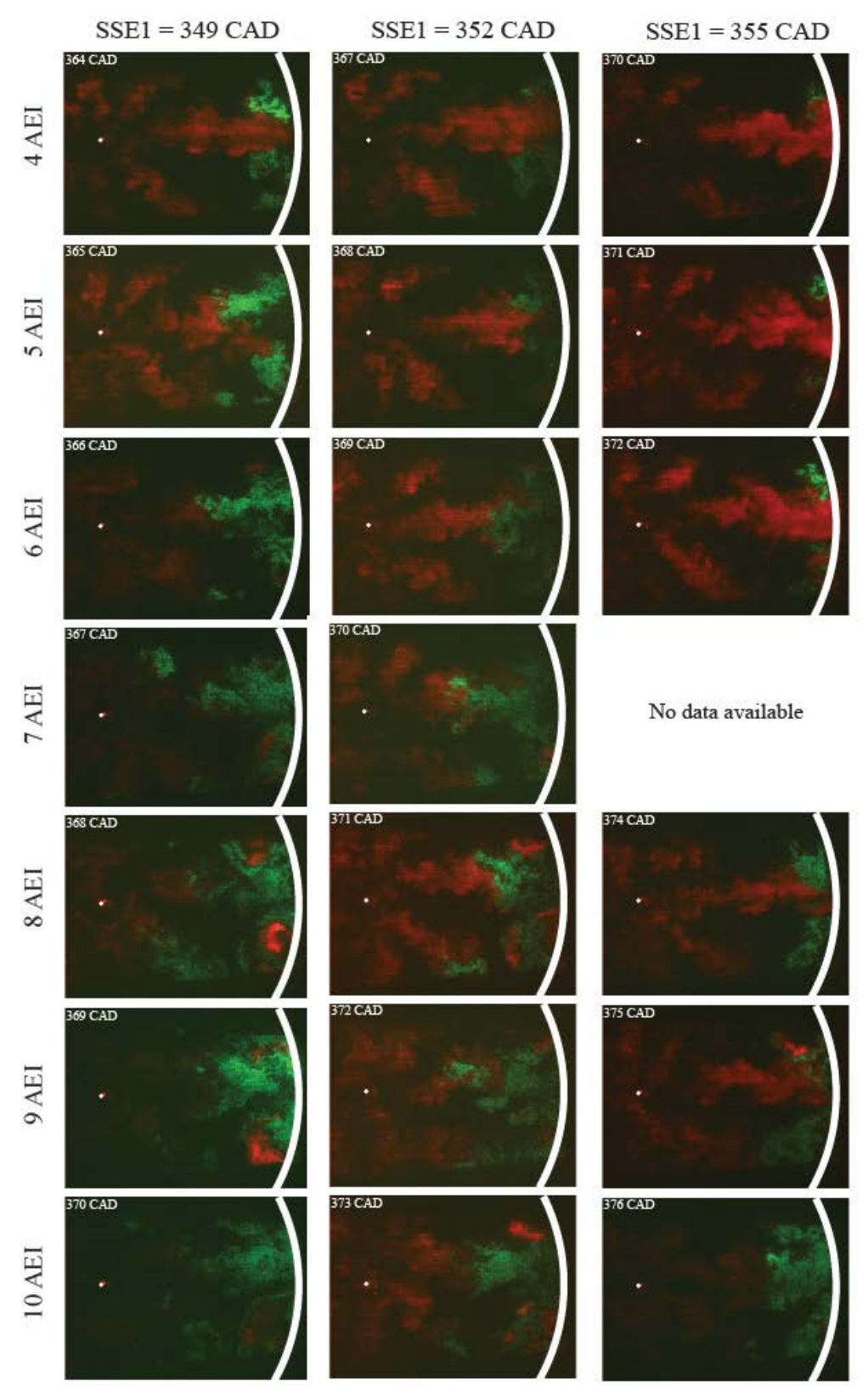

Figure 2. Evolution of combustion as seen through single-shot simultaneous OH-PLIF (green) and $\mathrm{CH}_{2} \mathrm{O}$-PLIF (red) imaging for a single-injection case at three injection timings, each with a duration of DSE1=1000 microseconds. Timings marked on the left side are given in number of crank angles after the end of injection (AEI), and the bowl wall and injector location are marked with the white line on the right and the white dot on the left, respectively. 


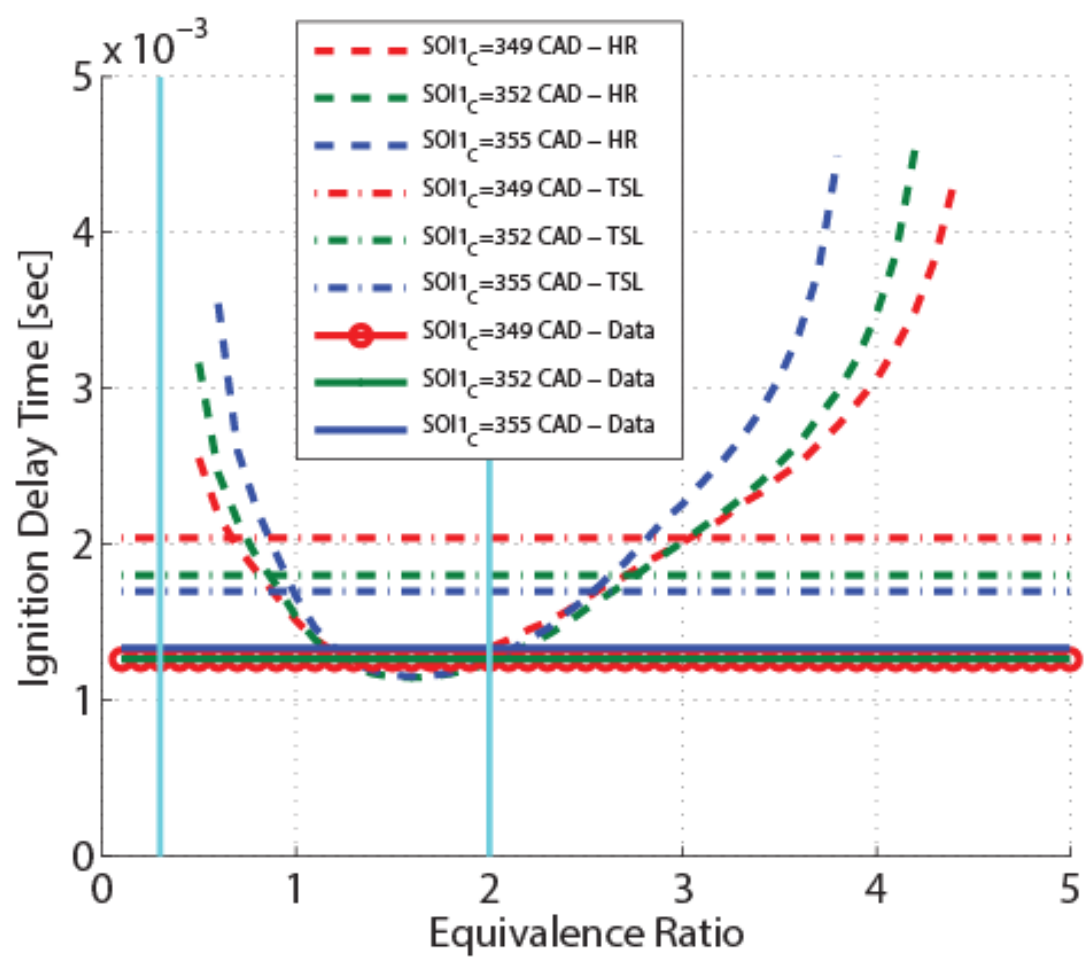

Figure 3. Experimentally measured engine ignition delay time (Exp.-solid), and calculations using Chemkin homogeneous reactor simulation (HR-dashed) and Chemkin TSL model (TSL-dot-dashed) for three injection timings, SSE1=349 CAD (red), SSE1=352 CAD (green), and SSE1=355 CAD (blue), over an equivalence ratio range of 0.1 to 5 . Equivalence ratio ranges over which data are not present indicate that these mixtures did not ignite during the 5ms homogeneous-reactor simulation. Vertical cyan lines indicate the limits of the n-heptane mechanism validation. 


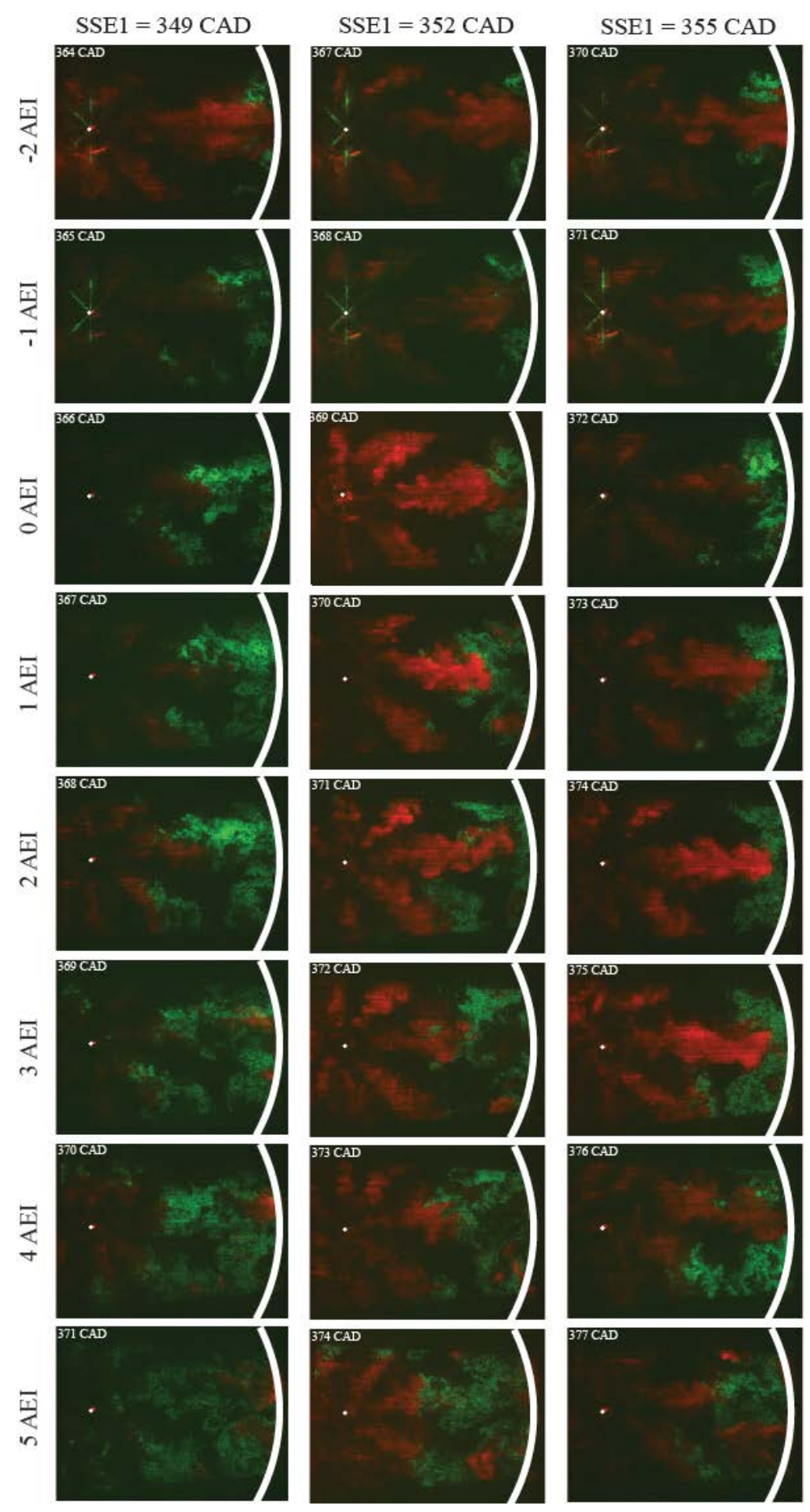

Figure 4. Single-shot simultaneous $\mathrm{OH}-\mathrm{PLIF}$ (green) and $\mathrm{CH}_{2} \mathrm{O}-\mathrm{PLIF}$ (red) imaging for a main- plus post-injection case at three injection timings, each with a main-injection duration 
of DSE1=1000 microseconds, a post-injection duration of DSE2=400 microseconds, and injection dwell of 210 microseconds.

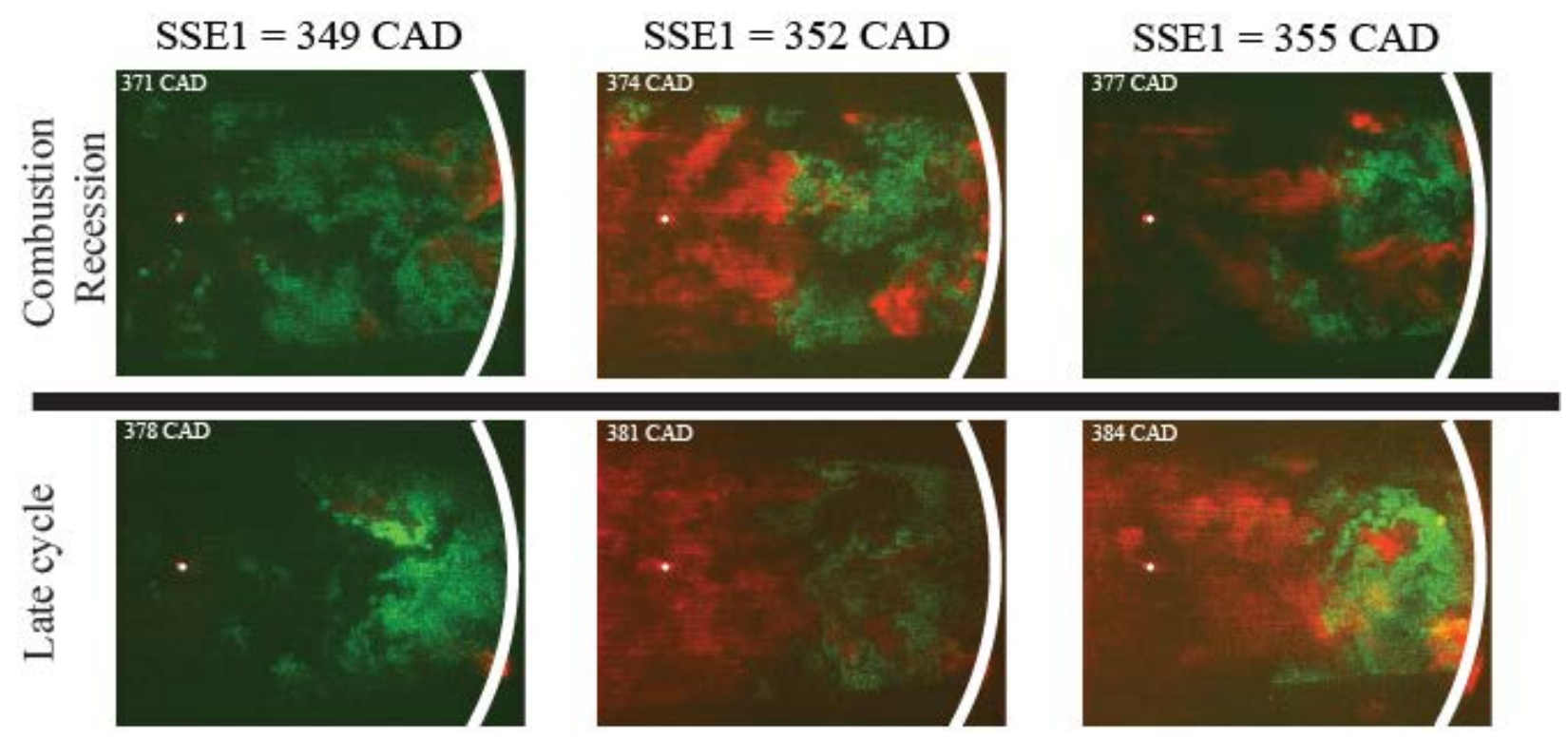

Figure 5. $\mathrm{OH}-\mathrm{PLIF} / \mathrm{CH}_{2} \mathrm{O}-\mathrm{PLIF}$ images showing comparison of the furthest extent of second-stage ignition, or combustion recession, (top) and late-cycle second-stage combustion (bottom) between three injection timings. 


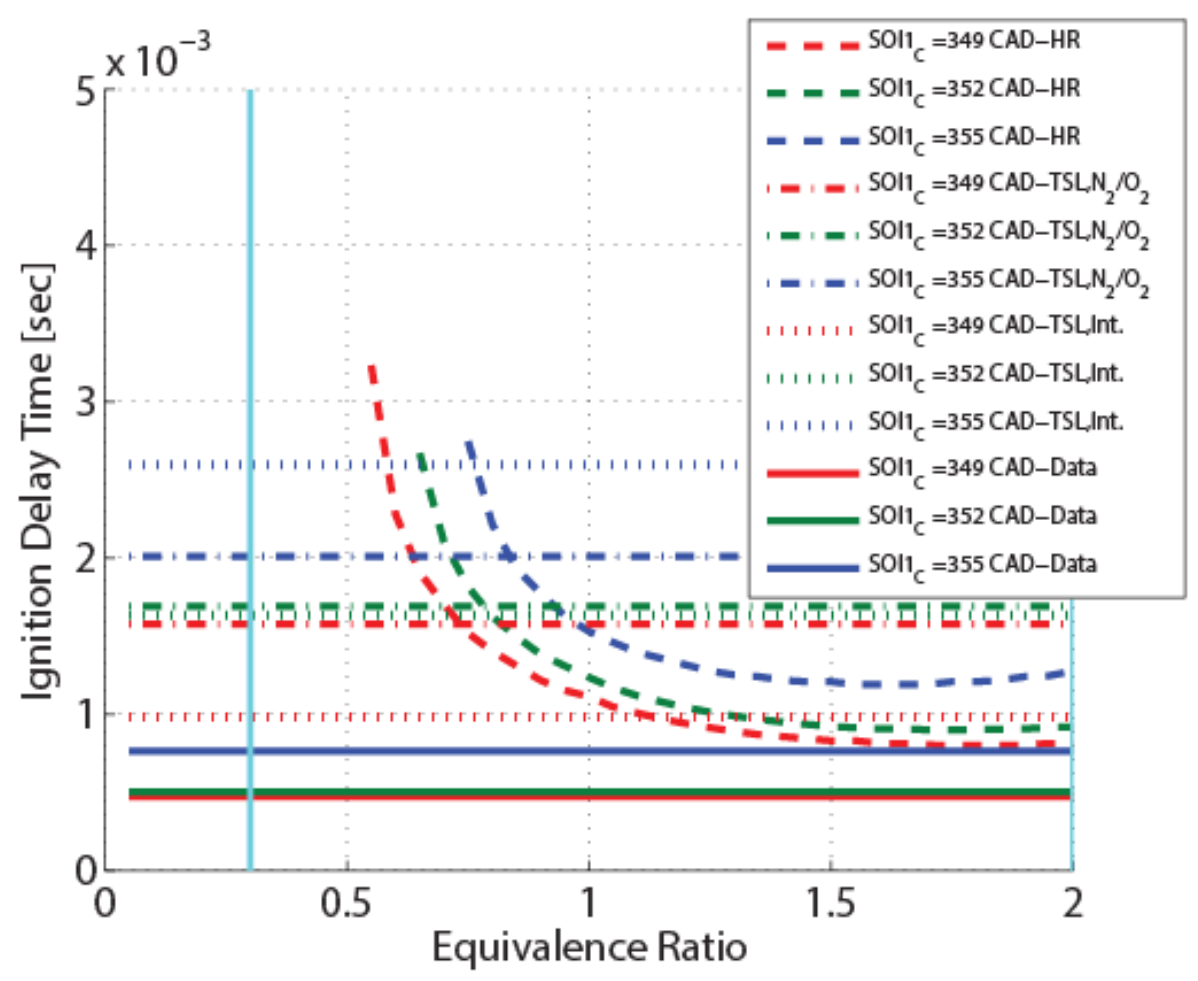

Figure 6. Ignition delay time calculations using Chemkin homogeneous reactor simulation with varying pressure for post-injection mixtures at three injection timings, SSE1=349 CAD (red), SSE1=352 CAD (green), and SSE1=355 CAD (blue), over an equivalence ratio range of 0.05 to 2 in 0.05 increments. Equivalence ratio ranges on the lean side over which data are not present indicate that these mixtures did not ignite during the simulation. Vertical cyan lines indicate the limits of the n-heptane mechanism validation. 


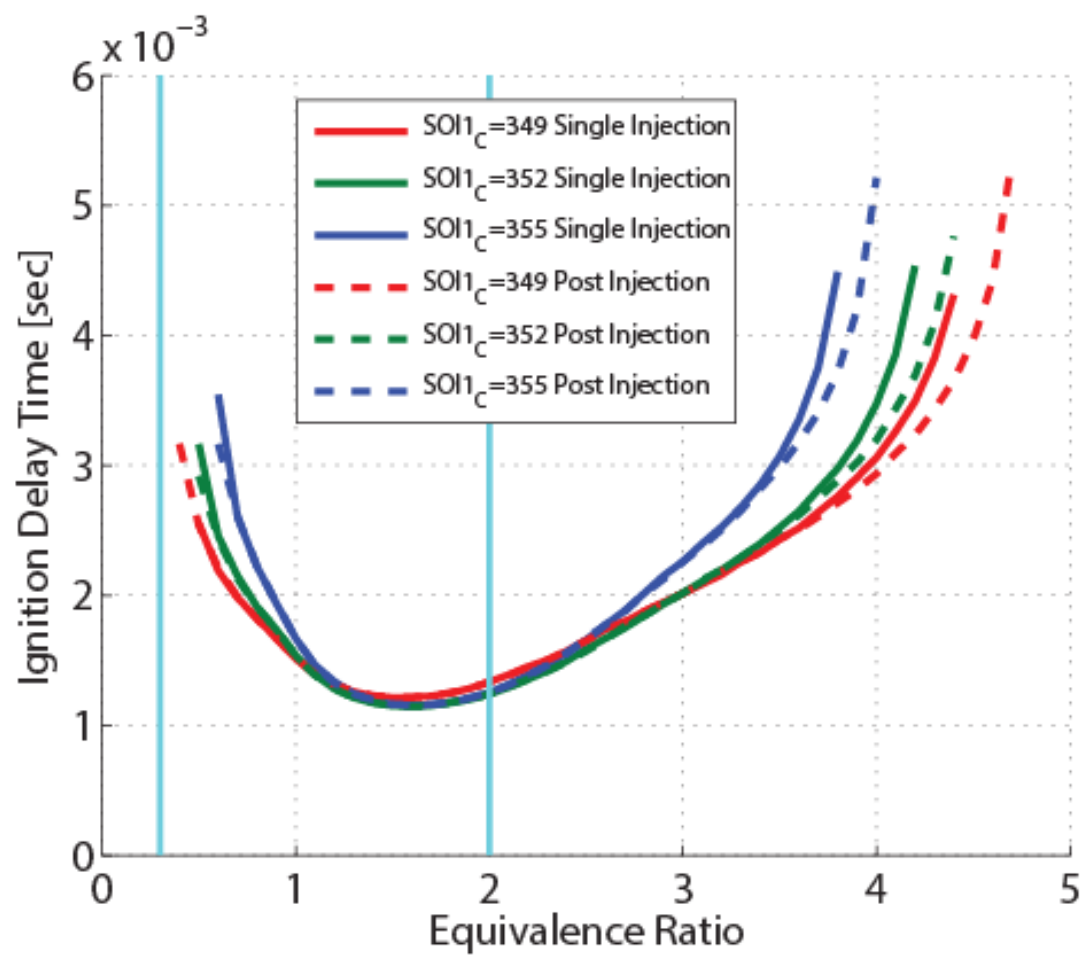

Figure 7. Ignition-delay time predictions using Chemkin homogeneous reactor simulation with single-injection pressure (solid) and main-plus post-injection pressure (dashed) series for mixtures at three injection timings, SSE1=349 CAD (red), SSE1=352 CAD (green), and SSE1=355 CAD (blue), over an equivalence ratio range of 0.1 to 5 in 0.1 increments. Equivalence ratio ranges over which data are not present indicate that these mixtures did not ignite during the simulation. Vertical cyan lines indicate the limits of the n-heptane mechanism validation. 


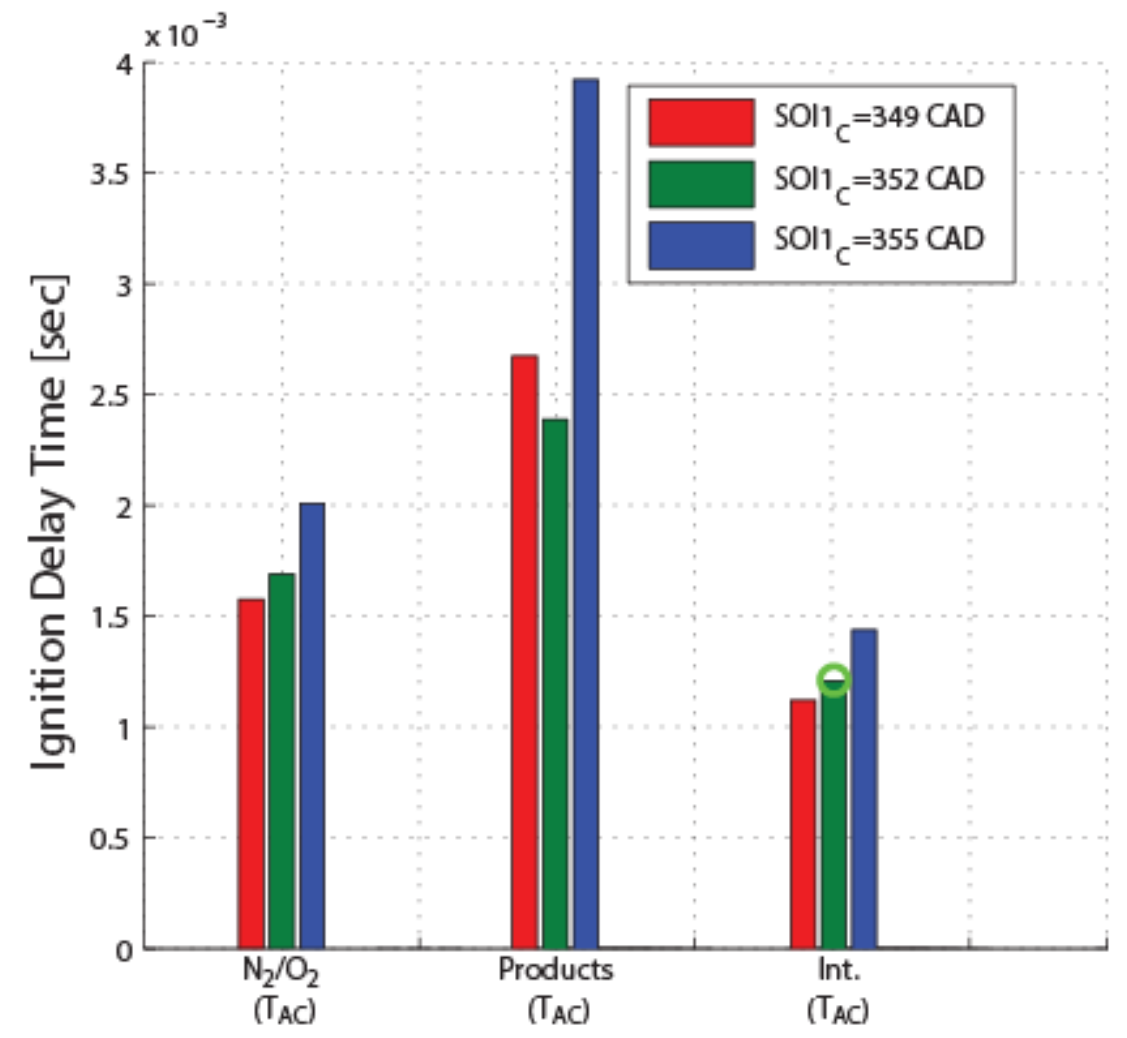

Figure 8. Ignition delay calculations with the Chemkin TSL model for a variety of entrainment gas compositions, as described in Error! Reference source not found.. Green circle indicates calculation with 21 surrounding species rather than 7 as in the other three calculations. 